\title{
The Innervation of Taste Buds in the Soft Palate of the Rat as Revealed by Methylene Blue Staining
}

\author{
Thomas MüLLER \\ Department of Anatomy, University of Mainz, Mainz, Germany \\ Received October 24, 1995
}

\begin{abstract}
Summary. Light microscopic data on the innervation of taste buds in the soft palate of the rat obtained by methylene blue (MB) supravital staining are presented here for the first time. The taste pore including subpopulations of taste bud cells and nerve fibers were stained. Intragemmal nerve fibers were detected ascending up to the taste pore; this suggests the possibility of additional paracellular pathways in taste transduction directly via nerve fibers. Moreover, relatively large bulbous or laminar enlargements of the intragemmal nerve fibers were found. The branches of these nerye fibers, showing minute spiny protuberances, appeared to anastomose. Some perigemmal nerve fibers were also seen in close apposition to the taste pore. The basal plexus in the vicinity of the taste buds showed enlargements which resembled the Merkel's discs, but were significantly smaller. These structures did not occur in the subgemmal part of the basal plexus. Regarding the oxygen-dependency of the staining reaction, it was speculated that both MB and oxygen were attracted by iron-containing enzymes. Therefore, the strong affinities for MB shown by subpopulations of nerve fibers and taste bud cells were explained by their high requirements for oxygen. Furthermore due to its selectivity for intraepithelial nerve fibers and sensory cells, the method applied here is well-suited for routine use in light microscopy.
\end{abstract}

Many light microscopic data on the innervation of taste buds in mammals are based on very early studies performed by means of silver impregnation and supravital methylene blue (MB) staining (ARNSTEIN, 1893; BoteZAT, 1902; Kolmer, 1910, 1927; RETZIUS, 1912). The MB technique represents a selective staining technique for neurons and sensory cells (EHRLICH, 1886); the dye is applied by intracardiac, intravascular or submucous injection followed by an exposure of the tissues to the air. When the development of the stain has reached its optimum, fixation is carrried out, which leads to a precipitation of the dye and to a preservation of the tissue structure. Unfortunately, all the former $\mathrm{MB}$ investigations listed above were documented only by drawings.

Subsequently a series of neuron-specific proteins and neuropeptides were detected within taste bud innervating nerve fibers by immunohistochemistry (NAGY et al., 1982; NisHIMOTO et al., 1982; FINGER, 1986; YOSHIE et al., 1988, 1989; SILVERMAN and KRUGER, 1989; FINGER et al., 1990; MontAVON and LindSTRAND, 1991a, b; IwANAGA et al., 1992). The innervation of taste buds was further investigated by the application of wheat germ agglutinin-horseradish peroxidase (CHAN and BYERS, 1985; BRADLEY et al., 1986); similar results were also obtained by staining with the fluorescent dye DiI (FINGER and BÖTTGER, 1990; NAGAI, 1993). Unfortunately, regarding the morphological details, the resulting images of these studies did not fully attain the quality of those obtained by conventional histological methods, i.e. MB staining and silver impregnation. It therefore seemed a worthwhile attempt to apply the MB procedure again to a closer investigation of the taste bud nerve fibers. Since descriptions regarding the staining method were judged insufficient in the literature, a modification of this procedure was worked out by the author to allow the production of paraffin sections of stained tissues without any loss of dye (MÜLLER and REUTTER, 1991). Dye storage within the taste pore and taste bud cells was also investigated under the electron microscope (MÜLLER and REUTTER, 1995). However, no detailed light microscopic MB-investigation on the innervation of mammalian taste buds has been performed using the author's modified staining procedure. Therefore, this technique has now been applied for a closer examination of the innervation pattern of taste buds in the soft palate of the rat. This region of the oral mucosa was used because all the previously mentioned MB-studies of mammalian taste buds were confined to those of the tongue. 


\section{MATERIALS AND METHODS}

Adult Sprague-Dawley rats were used for the experiments. The animals were killed with diethyl ether. Immediately thereafter, a $0.25 \%$ dye solution (MB med. puriss., C.I. 52015; Chroma, Köngen, Germany) was injected subepithelially into soft palate. The mucosa was then removed and exposed to the air in a moist chamber for $25-24 \mathrm{~min}$ at $20^{\circ} \mathrm{C}$. In some cases, storage of the specimens in the moist chamber was carried out in pure nitrogen or carbogen dioxide.

After the dye had spread, fixation and embedding in paraffin were done in a modified manner according to the authors' descriptions (MÜLLER and REUTTER, 1991): the first fixation was performed at $4^{\circ} \mathrm{C}$ (refrigerator) for $5 \mathrm{~h}$ (stock solution: $100 \mathrm{ml}$ of a $9 \%$ aqueous ammonium heptamolybdate solution with the addition of 9 drops of $25 \%$ hydrochloric acid and 0.9 $\mathrm{ml} \mathrm{30 \%} \mathrm{hydrogen} \mathrm{peroxide).} \mathrm{After} \mathrm{a} \mathrm{short} \mathrm{rinse} \mathrm{in}$ distilled water, a second fixation took place for $2 \mathrm{~h} 30$ min at $4^{\circ} \mathrm{C}$ [stock solution: $100 \mathrm{ml}$ of $2 \%$ paraformaldehyde and $2.5 \%$ glutaraldehyde in $0.1 \mathrm{M}$ phosphate buffer (pH 7.4) containing 1.8\% phosphomolybdic acid and $0.1 \%$ hydrogen peroxide (final $\mathrm{pH} 5.0$ )]. Following this, the specimens were washed overnight in distilled water.

Subsequently, some specimens were transferred through $20 \%$ aqueous sucrose and embedded in gelatine. The tissue blocks were then rapidly frozen and sectioned on a freezing-microtome. The 20-40 $\mu \mathrm{m}$ thick sections were mounted on glass slides and air-dried. They were transferred through xylene and coverslipped with DePeX ${ }^{\circledR}$ (Serva, Heidelberg, Germany).

For embedding in paraffin, the tissues were dehydrated in $100 \%$ tertiary butanol (melting point: $25^{\circ} \mathrm{C}$ ) for $48 \mathrm{~h}$. The first alcohol change was performed after $15 \mathrm{~min}$, the second after $1 \mathrm{~h}$ and the third after $7 \mathrm{~h}$. For these three preliminary dehydration steps, phosphomolybdic acid was added to the alcohol at a concentration of $0.05 \%$. The tissues were then transferred into pure tertiary butanol. After dehydration, they were stored for $1 \mathrm{~h}$ in a mixture of 8 parts decahydronaphthalene (Dekalin ${ }^{\circledR}$; Chroma, Köngen, Germany) and 2 parts methyl benzoate. Before embedding in paraffin, they were immersed for another hour in $100 \%$ decahydronaphthalene. The sections were mounted on glass slides. After drying, they were deparaffinized in xylene and coverslipped as described.

Due to the thickness of the paraffin sections combined with the 3-dimensional structure of the taste buds and the winding routes of the nerve fibers, the stained structures were focussed and photographed on different planes. Photomontages were therefore required to document the innervation pattern of the taste buds.

\section{RESULTS}

Intensely blue stained nerve fibers were observed within the subepithelial connective tissue; some nerve fibers also penetrated the epithelium as well as the taste buds (Figs. 1-11). In some cases, even taste bud cells stored the dye (Fig. 1), but in most cases only nerve fibers were stained (Figs. 2-11). Sometimes only single nerve fibers were stained; this enabled the investigator to study their routes and arborizations in detail. Regarding the taste bud innervation, the three classic types of nerve fibers could be detected: the basal nerve fiber plexus and the intragemmal nerve fibers were located within the taste buds, with the perigemmal nerve fibers in the vicinity.

The intragemmal nerve fibers could be studied more closely: they very often showed bulbous or laminar enlargements (Fig. 2). In some taste buds, these structures were significantly increased in size (Figs. 5-8). In the obviously early phase of staining, primarily the regions of the plasma membranes of the nerve fibers were stained, whereas their axoplasm remained only slightly stained (Figs. 8, 9). In addition, a branching of the intragemmal nerve fibers could be seen (Figs. 2, 6, 7); these branches showed minute spiny protuberances and seemed to be interconnected by anastomoses (Fig. 7). Furthermore, a second type of intragemmal nerve fiber could be observed which stretched up from the subepithelial connective tissue up to the taste pore, in which it seemed to end (Figs. $5,6)$.

The perigemmal fibers also showed interesting morphological characteristics (Figs. 3, 4, 8-11). They reached the superficial cell layers of the epithelium, where they very often branched (Figs. 4, 10). In some cases, these collaterals took a typical route parallel to the surface of the epithelium (Fig. 10). Intimate associations of perigemmal nerve fibers with taste pores were also detected (Figs. 3, 4). A subpopulation of perigemmal nerve fibers showed bulbous endings of different sizes in the superficial epithelial cell layers (Figs. 10,11). Their origin in the basal plexus seemed also to be of particular interest. Contrary to the region of the subgemmal plexus, the basal plexus in the vicinity of the taste buds showed characteristic enlargements of varying sizes (Fig. 11).

In general, the features of the stained nerve fiber enlargements also differed significantly in shape: some 

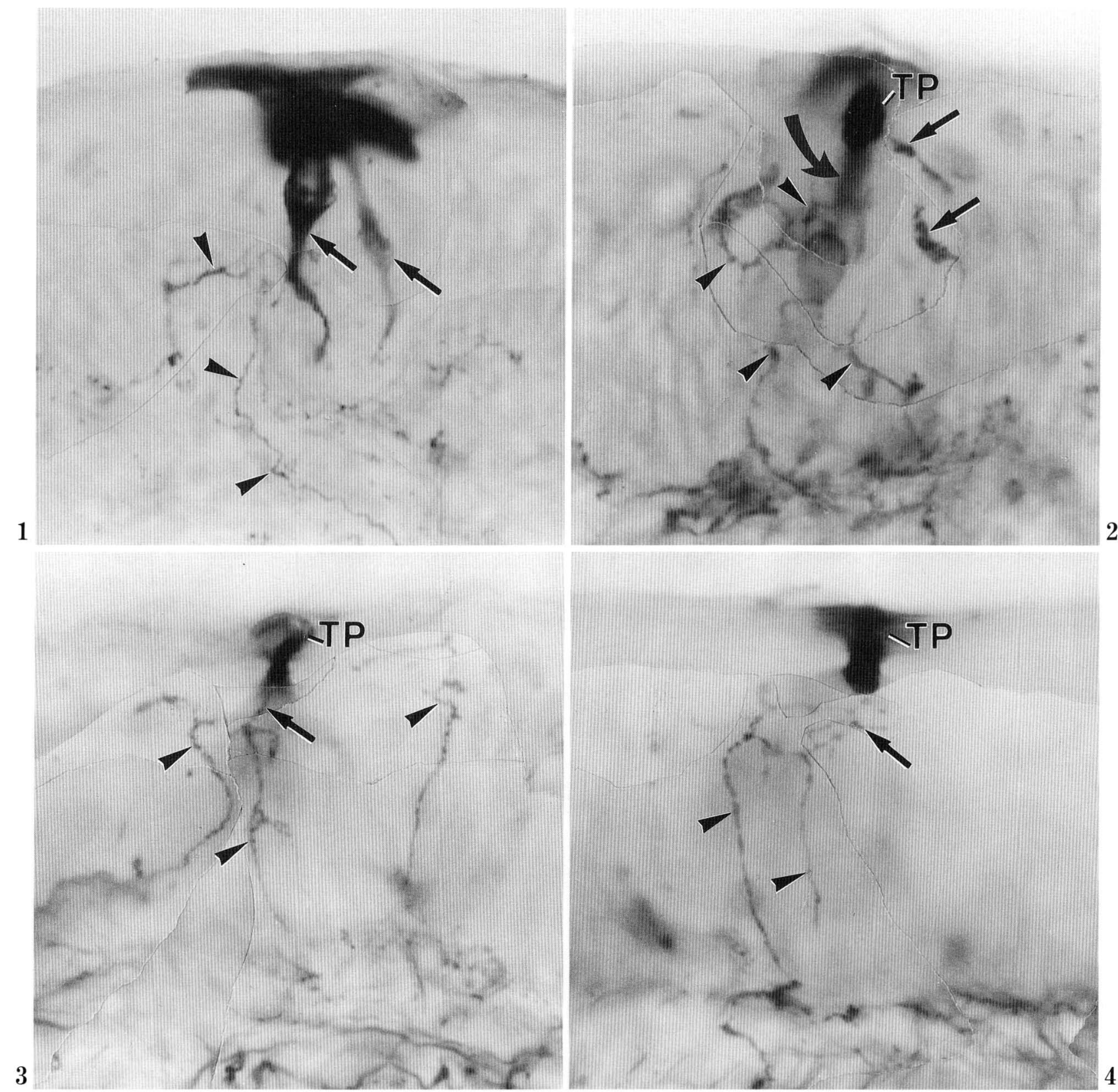

Fig. 1. A rat taste bud in the soft palate stained with methylene blue. Additionally to nerve fibers (arrowheads), two taste bud cells (arrows) are stained. Paraffin section. $\times 950$

Fig. 2. Within a taste bud, delicate intragemmal nerve fibers (arrowheads) branch and take loop-like routes. Terminal enlargements (arrows) of other nerve fibers are also visible; the upper one is situated close to the taste pore (TP). The apical part of a taste bud cell (curved arrow) is also stained. Paraffin section. $\times 1,000$

Fig. 3. Close to a taste bud, three perigemmal nerve fibers (arrowheads) ascend up to the superficial layers of the epithelium; one (arrow) appears to innervate the taste pore (TP). Paraffin section. $\times 950$

Fig. 4. Stained perigemmal nerve fibers (arrowheads) in the vicinity of a taste bud. They stretch towards the surface, where they divide and form a delicate plexus; in part, the thin branches end in the vicinity of the taste pore $(T P)$. Paraffin section. $\times 950$ 

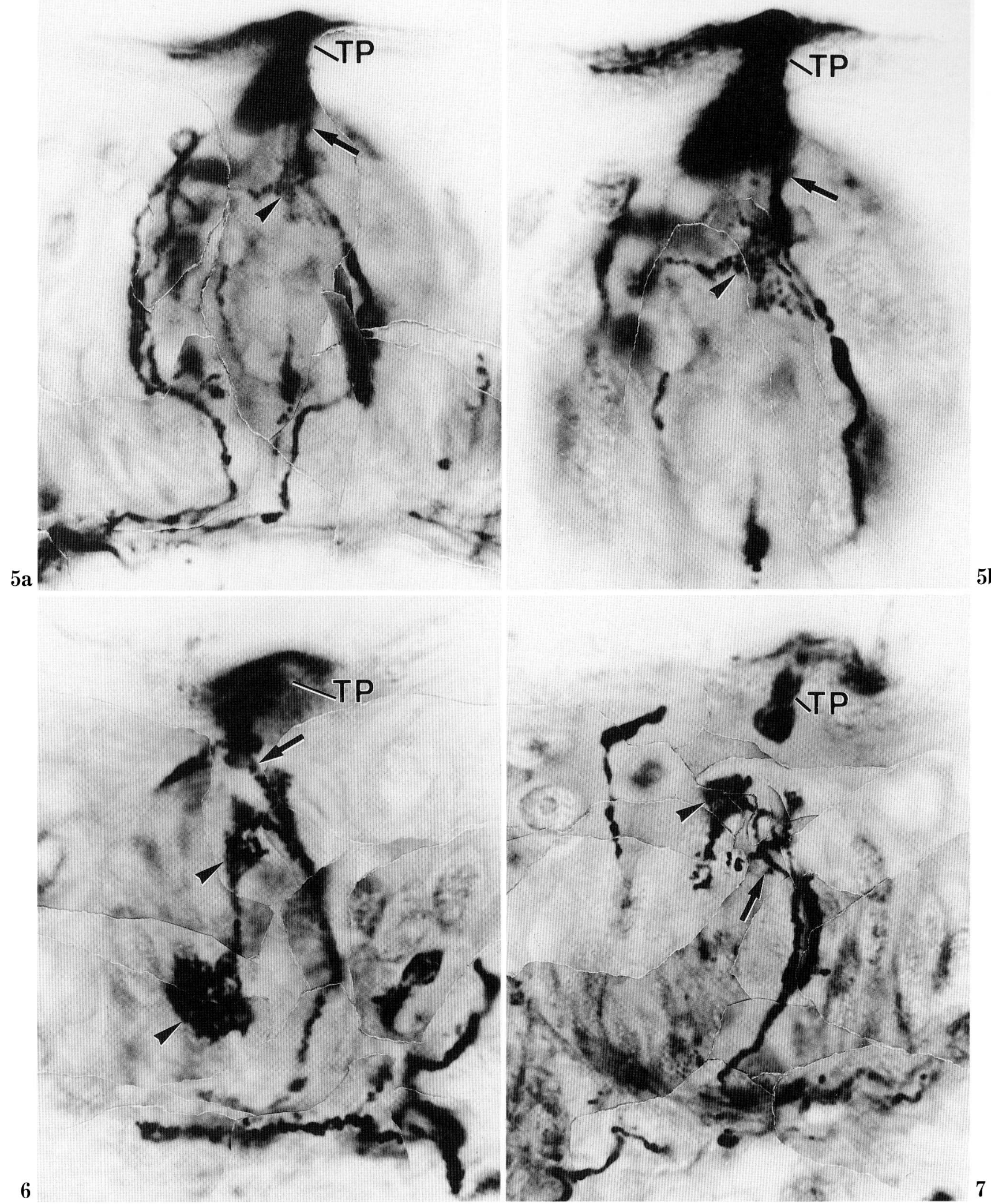

Figs. 5-7. Legends on the opposite page. 


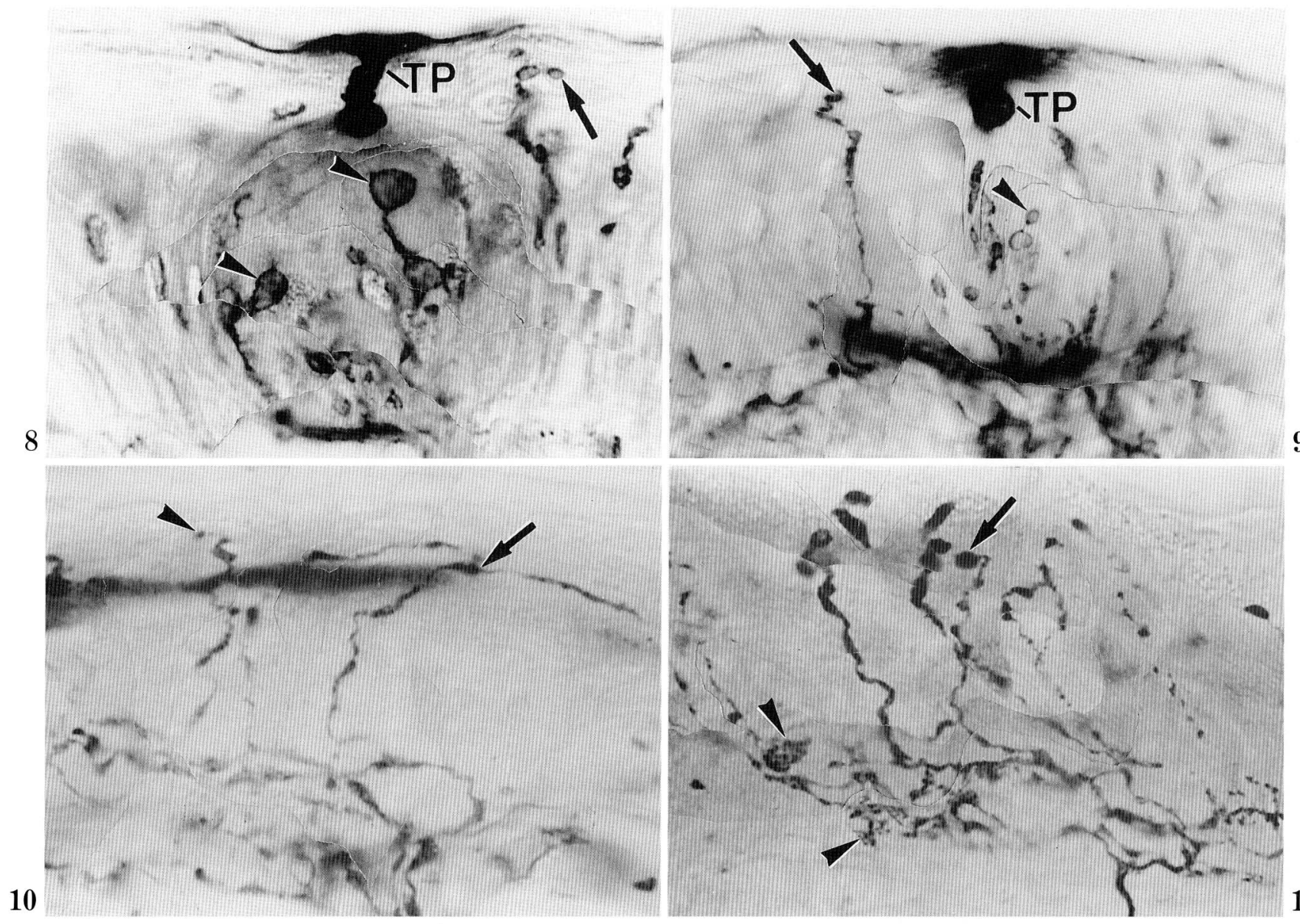

Fig. 8. A taste bud in the initial phase of staining. Oversized enlargements (arrowheads) of intragemmal nerve fibers can be detected. The ending of an adjacent perigemmal nerve fiber is normal in size (arrow). All the nerve fibers show primarily a staining of the region of the plasma membrane in addition to a less intensive staining of the axoplasm. TP taste pore. Paraffin section. $\times 950$

Fig. 9. A taste bud in the early phase of dye uptake. Compared with Figure 8, the intragemmal nerve fibers show varicosities which are significantly smaller in size (arrowhead); a perigemmal nerve fiber is also stained (arrow). The plasma membranes of the axons appear to be mainly stained. $\times 950$

Fig. 10. The innervation of the epithelium in the vicinity of a taste bud. The taste bud is not situated in the plane of the section. Perigemmal nerve fibers originate from a basal nerve fiber plexus. Their superficial terminations differ significantly in shape: some divide (arrow), sending off branches which run parallel to the surface; others end without branching (arrowhead). The taste bud is not sectioned. Frozen section. $\times 1,250$

Fig. 11. Nerve fibers within the epithelium close to a taste bud. The adjacent taste bud is located outside the plane of the section. In part, the perigemmal or intergemmal nerve fibers end as relatively large bulbous swellings (arrow). The basal plexus shows laminar enlargements of the nerve fibers (arrowheads) which differ in size. The adjacent taste bud is not located in the plane of the section. Frozen section. $\times 1,050$

Fig. 5. Innervation of the taste pore. a. The penetration of the taste pore (TP) by an intragemmal nerve fiber is easily identifiable (arrow). Just beneath it, the intragemmal nerve fiber shows a lateral laminar enlargement (arrowhead). b. A higher magnification demonstrates the taste pore (TP) innervation (arrow) and the lateral enlargement (arrowhead) of the nerve fiber in detail. Paraffin section. a: $\times 1,650 ; \mathrm{b}: \times 2,400$

Fig. 6. Innervation of the taste pore (TP) by an intragemmal nerve fiber (arrow). The intragemmal nerve fiber is further characterized by a branch with oversized swellings (arrowheads). Paraffin section. $\times 2,100$

Fig. 7. An intragemmal nerve fiber showing a complicate arborization pattern inside a taste bud. One branch exhibits a bulbous enlargement (arrowhead). In addition, the collaterals exhibit spiny protuberances (arrow). Moreover, anastomoses seem to occur between the branches of the intragemmal nerve fiber. The taste pore (TP) is also stained. Paraffin section. $\times 1,800$ 
exhibited smooth outlines (Figs. 2-4, 8, 9), whereas others were notched (Figs. 6, 7).

The absence of oxygen in the moist chamber completely prevented any dye uptake by nerve fibers and taste bud cells; accordingly only the taste pores were stained.

Regarding the preservation of the tissue structures, the frozen sections were inferior to the paraffin sections. Nevertheless, interesting morphological details were also found in the frozen sections (Figs. 10, 11).

\section{DISCUSSION}

The most interesting result of the present study was the observation that MB staining is not only capable of visualizing taste bud cells and adjacent nerve fibers. Moreover, this method is also able to demonstrate differences in the routes and morphology of the nerve fibers. Here, it has to be emphasized that intragemmal nerve fibers could be found which ascended up to the taste pore. This suggests the possibility of paracellular pathways in taste transduction directly via the nerve fibers, and not only transcellularly via the taste bud cells. This was not surprising because the taste reception of salts is not principally confined to the occurrence of taste bud cells; in amphibians, neuronal taste responses can be detected following the administration of salts to taste bud-free skin regions (VON SECKENDORFF HOFF and HILlYARD, 1993). In mammals, additional paracellular pathways in the transduction of salty taste are also assumed (SIMON et al., 1993). The demonstrated innervation of the taste pore contradicts the findings of other investigators obtained by silver impregnation (KOLMER, 1910; ENGSTRÖM and RYTZNER, 1956; KADANOFF and GÜROWSKI, 1963). However, BotezAT (1902) and Retzius (1912) published drawings which showed also intragemmal nerve fibers ending within the taste pore. Nishimoto et al. (1982) found substance $P$ containing nerve fibers terminating near the taste pores. Another alternative function of the taste pore innervating intragemmal nerve fibers might be the adaption of the taste pore aperture diameter and therefore the modulation of the access of taste bud cells to the stimuli by engaging the contractile apparatus of the taste pore (MATTERN and PARAN, 1974). Here, it has to be pointed out that the combined staining of the taste pores and nerve fibers, as achieved in the present study, made the identification of their intimate association significantly easier.

A further important finding was the observation of relatively large bulbous or laminar enlargements of intragemmal nerve fibers. The fact that they were not observed in all taste buds indicates differences in the function of the taste buds. They were also detected in the early phase of staining, where only the plasma membrane of the axons was stained. The adjacent perigemmal nerve fibers exhibited only minute varicosities which indicated that the enlargements were not caused by a toxic effect of the dye. Such swellings of the intragemmal nerve fibers could also be demonstrated by neuron-specific enolase immunohistochemistry in rat taste buds of the tongue, but not in those of the pig (MONTAVON and LindSTRAND, 1991a, b). In this context, it has to be pointed out that significant differences in the arrangement of the synapses between taste buds of the tongue and those of the palate were found under the electron microscope (LIEM et al., 1990). Due to these differences, taste buds outside the tongue have been called taste corpuscles or chemosensory corpuscles by some authors (RoDRIGO et al., 1980; LIEM et al., 1990).

In addition, the present study revealed that the intragemmal nerve fibers also showed minute spinous protuberances which have not been previously described in the literature. Furthermore, it was demonstrated that anastomoses apparently exist between delicate branches of the nerve fibers in the taste bud. These findings are in contrast to those of VON LENHOSSÉK (1893), but support the results of BoTEZAT (1902) and BoEkE (1925). Here it has to be emphasized that it was of course not possible to determine whether the anastomoses connect the branches of one neuron or two neurons; this last mentioned case is not very likely because it would contradict the neuron-theory.

A further important aspect is the morphology of the perigemmal nerve fibers which end just beneath the epithelial surface. Their morphology differed significantly from that of the intragemmal nerve fibers; this observation contradicts the opinion of KOLMER $(1910,1927)$ that intragemmal and perigemmal nerve fibers are identical in shape as well as function. Moreover, it has been shown that the taste bud nerve fibers possess different functions displayed by their different contents of neuropeptides (FINGER, 1986). Due to the accumulation of the perigemmal nerve fibers in the vicinity of taste buds as seen in the present study, they might also play a special role in taste reception; this is in full accordance with the interpretations of other investigators (ENGSTRÖM and RYTZNER, 1956; SiLVERMAN and KRUGER, 1989). Moreover, some endings of perigemmal nerve fibers were also seen in close association with the taste pore; this phenomenon is confirmed by the findings of former studies (FINGER, 1986; Silverman and KRUgER, 1989) This indicates a chemosensory function for at least subpopulations of these fibers or a special role in adaption of the taste pore's diameter (SILVERMAN and KRUGER, 1989). 
However, it cannot completely be ruled out that the taste buds fulfill various functions. In this context, the proven laminar enlargements of the nerve fibers forming the basal plexus in the vicinity of the taste buds, where the perigemmal nerve fibers originate, might be of particular interest; these structures resemble the Merkel's discs, but are significantly smaller. Therefore, they might have mechanoreceptive tasks.

The staining of the nerve fibers leads to the question of the staining mechanism. Since the selective staining of nerve fibers and sensory cells occurs only in the presence of oxygen, it was concluded that the redox dye MB stains intracellular oxygen binding sites (EHRLICH, 1886). Furthermore, it was supposed that intracellular iron is responsible for the simultaneous binding of oxygen and MB (KONDRATJEW, 1926). KIERNAN (1974) proved that a metal containing enzyme is most probably involved in the staining process. Moreover, it could be shown that MB interacts with many heme proteins (MAYER et al., 1993). In addition, the intracellular uptake of the dye is followed by the generation of short-lived oxygen radicals which are responsible for the toxic effects of the dye (LEE and WURSTER, 1995). Here, the observed differences in the shape of the nerve fiber enlargements displayed by smooth or notched outlines have to be discussed. Slight morphological alterations caused by the toxicity of the dye and the varying incubation times could not completely be excluded. However, unequivocal degenerative changes of the nerve fibers such as their decomposition occur normally only in the case of longer incubation times than are recommended in the present study.

If an iron-containing enzyme is actually the target of the dye, it is localized at the plasma membrane and within the cytoplasm outside the mitochondria, as could be shown electron microscopically (MÜLLER and REUTTER, 1996). Moreover, data in the literature indicate that $\mathrm{MB}$ is possibly reduced to its lipophilic leuco form by an unknown mechanism immediately before entering sensory and nerve cells; this uptake is followed by the intracellular reoxidation of the reduced dye to its blue positively charged form which is now able to bind to the chromatin within the nucleus (HARRIS and PETERS, 1953). The staining of the nuclei of the taste bud cells might be explained by a binding of the dye to nucleotides within the chromatin (SCHUBERT et al., 1995). It has to be mentioned that the transmembranous migration of the dye is assumed to take place by passive diffusion (KIERNAN, 1974). In addition, the question has been raised as to why some nerve fibers and taste bud cells show a stronger affinity to the dye than others. This staining behavior might be based on a relatively high requirement for oxygen by the dye storing nerve fibers and sensory cells. Furthermore, the staining of the taste pore has to be discussed. Electron microscopically, it can be shown that the dye is found to be accumulated primarily outside the cytoplasm of the microvillous endings of the taste bud cells within the mucus (MÜLLER and REUTTER, 1996). This binding of the cationic dye was deduced from the well-known occurrence of strongly anionic residues in the mucus; these negatively charged groups would attract the cationc organic dye. Only in the case of an excessive dye supply is a staining of taste bud cells and nerve fibers achieved. Here however, it has to be emphasized that the concrete staining mechanism is a matter of speculation and needs to be clarified more closely.

In conclusion, because of its high selectivity, ease in handling and ability to visualize morphological details, the technique described here is well-suited as a routine method for the light microscopic investigation of intraepithelial nerve fibers and sensory cells.

Acknowledgments. The author is indebted to Mrs. K. BAhr, Mrs. C. Peigney and Mrs. D. Volland, Department of Anatomy, University of Mainz, for their skilful technical assistance.

\section{REFERENCES}

Arnstein, C.: Die Nervenendigungen in den Schmeckbechern der Säuger. Arch. Mikrosk. Anat. 41: 195-218 (1893).

BoEkE, J.: Die intrazelluläre Lage der Nervenendigungen in Epithelgewebe und ihre Beziehungen zum Zellkern. Z. Mikrosk. Anat. Forsch. 2: 391-428 (1925).

Botezat, E.: Über das Verhalten der Nerven im Epithel der Säugethierzunge. Z. Wiss. Zool. 71: 211-226 (1902).

Bradley, R. M., C. M. Mitretta and T. Nagai: Demonstration of sensory innervation of rat tongue with anterogradely transported horseradish peroxidase. Brain Res. 367: 364-367 (1986).

Chan, K. Y. and M. R. BYERs: Anterograde axonal transport and intercellular transfer of WGA-HRP in trigeminal-innervated sensory receptors of rat incisive papilla. J. Comp. Neurol. 234: 201-217 (1985).

Ehrlich, P.: Ueber die Methylenblaureaction der lebenden Nervensubstanz. Deut. Med. Wochenschr. 12: 49-52 (1886).

Engström, H. and C. Rytzner: The fine structure of taste buds and taste fibres. Ann. Otol. Rhinol. Laryngol. 65: 361-365 (1956).

Finger, T. E.: Peptide immunohistochemistry demonstrates multiple classes of perigemmal nerve fibers in the circumvallate papilla of the rat. Chem. Senses 11: 135-144 (1986) 
Finger, T. E. and B. BötTGER: Transcellular labeling of taste bud cells by carbocyanine dye (diI) applied to peripheral nerves in the barbels of the catfish, Ictalurus punctatus. J. Comp. Neurol. 302: 884-892 (1990).

Finger, T. E., M. Womble, J. C. Kinnamon and T. UEDA: Synapsin I-like immunoreactivity in nerve fibers associated with lingual taste buds of the rat. J. Comp. Neurol. 292: 283-290 (1990).

Harris, J. E. and A. Peters: Experiments on vital staining with methylene blue. Quart. J. Microsc. Sci. 94 : 113-124 (1953).

IwanaGa, T., H. HaN, H. Kanazawa and T. FuJITA: Immunohistochemical localization of protein gene product 9.5 (PGP 9.5) in sensory paraneurons of the rat. Biomed. Res. 13: 225-230 (1992).

KADAnofF, D. and A. Gü Rowski: Morphologie der Rezeptoren des Atmungs- und Verdauungssystems beim Menschen. Fischer, Jena, 1963.

KIERNAN, J. A.: Effects of metabolic inhibitors on vital staining with methylene blue. Histochemistry $40: 51-57$ (1974).

Kolmer, W.: Ueber Strukturen im Epithel der Sinnesorgane. Anat. Anz. 36: 281-299 (1910).

- : Geschmacksorgan. In: (ed. by) W. V. MöLLENDORFF: Handbuch der mikroskopischen Anatomie des Menschen, III/1. Springer, Berlin, 1927 (p. 154-191).

KondRatJEw, N. S.: Eine neue Methode der elektiven makroskopischen Färbung des Nervensystems. Z. Anat. Entw.-Gesch. 78: 669-681 (1926).

LEE, Y. S. and R. D. WuRster: Methylene blue induces cytotoxicity in human brain tumor cells. Cancer Lett. 88: 141-145 (1995).

Liem, R. S., J. D. Van Willigen, J. C. Copray and G. J. Terhorst: Corpuscular bodies in the soft palate of the rat. 1. Morphology and distribution. Acta Anat. 138: 5664 (1990).

Mattern, C. F. T. and N. Paran : Evidence of a contractile mechanism in the taste bud of the mouse fungiform papilla. Exp. Neurol. 44: 461-469 (1974).

MAYER, B., F. BRUNNER and K. SchmidT: Inhibition of nitric oxide synthesis by methylene blue. Biochem. Pharmacol. 45: 367-374 (1993).

Montavon, P. and K. Lindstrand: Immunohistochemical localization of neuron-specific enolase and calcitonin gene-related peptide in rat taste papillae. Regul. Pept. 36: 219-233 (1991a).

- : Immunohistochemical localization of neuron-specific enolase and calcitonin gene-related peptide in pig taste papillae. Regul. Pept. 36: 235-248 (1991b)

MÜLLER, T. and K. REUTTER: Demonstration of taste bud innervation of fish and mouse in paraffin sections by intravital methylene blue injections. Anat. Anz. 170, Suppl.: 311-313 (1991).

- : Light and electron microscopical demonstration of methylene blue accumulation sites in taste buds of fish and mouse after supravital dye injection. Anat. Embryol. 192: 537-545 (1995).
NagaI, T.: Transcellular labeling by diI demonstrates the glossopharygeal innervation of taste buds in the lingual epithelium of the axolotl. J. Comp. Neurol. 331: 122-133 (1993).

Nagy, J. I., M. Goedert, S. P. Hunt and A. Bond: The nature of the substance P-containing nerve fibres in taste papillae of the rat tongue. Neuroscience $7: 3137-$ 3151 (1982).

Nishimoto, T., M. Akai, S. Inagaki, S. Shiosaka, Y. Shimizu, K. Yamamoto, E. Senba, M. SaKanaKa, K. Takatsuki, Y. Hara, H. Takagi, T. Matsuzaki, Y. KaWAI and M. Tohyama: On the distribution and origins of substance $\mathrm{P}$ in the papillae of the rat tongue: an experimental and immunohistochemical study. J. Comp. Neurol. 207: 85-92 (1982).

RETziUs, G.: Zur Kenntnis der Geschmacksknospen beim Kaninchen. Biol. Untersuch. 17: 72-81 (1912).

Rodrigo, J., E. M. Robles Chillida, F. Espinosa, J. Defelipe, J. Hernández, A. Arnedo and J. Mayo: New contribution on the oesophageal mucous innervation in certain monkeys (Cercopitheciae). Acta Anat. 108: 510-520 (1980).

Schubert, F., A. KNaF, U. Möller and D. CEH: Covalent attachment of methylene blue to oligonucleotides. Nucleosides \& Nucleotides 14: 1437-1443 (1995).

Silverman, J. D. and L. Kruger: Calcitonin-generelated-peptide-immunoreactive innervation of the rat head with emphasis on specialized sensory structures. J. Comp. Neurol. 280: 303-330 (1989).

Simon, S. A., V. F. Holland, D. J. Benos and G. A. ZAMPIGHI: Transcellular and paracellular pathways in lingual epithelia and their influence in taste transduction. Microsc. Res. Techn. 26: 196-208 (1993).

Von Lenhossék, M.: Der feinere Bau und die Nervenendigungen der Geschmacksknospen. Anat. Anz. 8: 121127 (1893).

Von Seckendorff HofF, K. and S. D. Hillyard: Toads taste sodium with their skin: sensory function in a transporting epithelium. J. Exp. Biol. 183: 347-351 (1993).

Yoshie, S., C. Wakasugi, Y. Teraki, T. Iwanaga and T. FuJITA: Immunocytochemical localizations of neuronspecific proteins in the taste bud of the guinea pig. Arch. Histol. Cytol. 51: 379-384 (1988).

Yoshie, S., Y. Teraki, T. Iwanaga and T. Fujita: Immunocytochemistry of neuron-specific proteins and neuropeptides in taste buds and associated nerves. Arch. Histol. Cytol. 52, Suppl.: 389-396 (1989).

Dr. Thomas MüLLER

Department of Anatomy

University of Mainz

Saarstr. 19-21

D-55099 Mainz, Germany 